\title{
Quality of life and self-esteem of women who practice Pilates
}

Francineide Rocha de Aguiar Oliveira', Olga Lorena Maluf Guará2 ${ }^{2}$ Aline Fróes³ ${ }^{3}$ Marcelo Cardoso de Souza4, Renata Trajano Jorge Caldas ${ }^{5}$

\begin{abstract}
Introduction: The Pilates Method has been excelled as an activity that values the functional capacity, coordination, strength, balance and cooperates for the well-being of those who practice it. Objective: This study evaluated the quality of life and self-esteem of women practicing the Pilates method. Methods: Descriptive and cross-sectional study with a sample of 60 women, 30 practitioners of the method (Pilates group) and 30 non-practitioners (control group). For data collection were applied a socio-demographic data sheet and two other instruments: the SF-36, a generic quality of life questionnaire and the Rosenberg Self-esteem Scale, an instrument for measuring self-esteem. Results: Participated in the study 60 women, divided into Pilates group and control group. The groups were considered statistically similar with respect to age, schooling, marital status, work, housing and BMI. Regarding quality of life, there were only statistically significant differences between the groups for the general health domain ( $p \leq 0.001)$ and emotional aspects $(p=0.001)$ with better results for the Pilates group. For the self-esteem, there was no statistical difference between the groups ( $p=0.05)$. Conclusion: Women who practice Pilates present some aspects of quality of life (general health and emotional aspects) in superiority to those who do not practice it.
\end{abstract}

Keywords: Pilates; Quality of Life; Self-Esteem.

\section{INTRODUCTION}

The modern world has dramatically altered the lifestyle of women, forcing them to unfold in various activities to meet professional, family, domestic and personal demands. As a result of this fact, arise consequences such as overload, stress, psychic and physical illnesses, especially the musculoskeletal ones ${ }^{(1)}$.

Contrary to modern day tasks and their drastic consequences, regular physical activity has emerged as a beneficial option for acquiring a healthy life by promoting a range of benefits such as a sense of well-being, reduced depression and anxiety, appetite and body weight control, blood pressure control, relief of musculoskeletal symptoms, among many others ${ }^{(2,3)}$.

For this reason, since the beginning of the 1990s, issues related to the practice of physical activity and the measurement of quality of life, health perception and global well-being, have become a common theme among scholars, presenting the diagnosis of the living conditions of the population in general( ${ }^{(4-6)}$.

The concept of quality of life is very broad, complex and multi-dimensional, but in general, it should be understood as the perception of physical, psychological and social health in daily activities, and not just related to the absence or presence of comorbidities ${ }^{(4-6)}$. Within this context, self-esteem, which is considered one of the human personality constructs and is a relevant indicator of mental health, is incorporated. Some authors define it as the image that every human being has of himself or as a tendency to believe, accept and love himself ${ }^{(7,8)}$.

Pilates is a method of physical and mental conditioning, which connects mind and body and consists of a variety of controlled and harmonic movements that can be performed on the ground, with balls or in devices equipped with a mechanism of springs that offer resistance or facilitate the execution of movements. Among the many options of physical activity, the method has been excelled as a practice that confers many benefits, especially the control of muscular pain, muscular strengthening, flexibility, postural reeducation, body balance and well-being ${ }^{(9-11)}$.

The motivation for the research was the lack of studies in healthy women that measure the quality of life and especially the self-esteem of individuals who practice Pilates. This study aimed to verify the quality of life and self-esteem of women 
practicing the Pilates method using the quality-of-life and self-esteem questionnaires, standardized and adapted to the Brazilian reality.

\section{METHODS}

\section{Type of Study}

This is an observational and cross-sectional study that was carried out in a Pilates studio located in the city of São Luís, Ma, Brazil.

\section{Participants}

The sample was selected for convenience and composed by two groups of women, a Pilates group and a control group, composed of sedentary women. For the Pilates group, the following inclusion criteria were adopted: women aged between 18 and 65 years who have been practicing Pilates for at least one month and with a minimum frequency of twice a week. Women who presented cognitive limitation, pregnant, amputated, neurological patients, or any other conditions that could alter the quality of life or that impaired the interview were not included. The control group was paired by gender and age and composed of individuals from the community.

\section{Instruments}

Data collection was done through a socio-demographic data sheet containing identification, age, gender, schooling, marital status, with whom they live, family satisfaction, type and place of residence, weight, height, occupation, among other questions. And also through the Short Form Health Survey - SF-36, validated and translated into Portuguese, which is a generic instrument for evaluation of quality of life that includes 36 items in eight components: functional capacity, physical aspects, pain, general health, vitality, social aspects, emotional aspects and mental health. In the calculation of each component, the final score varies from 0 to 100 , where 0 represents worse health and 100 better health of each component ${ }^{(4)}$. For the self-esteem evaluation, the Self-esteem Scale developed by Rosenberg was used, which is a one-dimensional measure that contains ten statements related to a set of feelings of self-esteem and self-acceptance that assess global self-esteem. The items are answered on a four-point Likert scale, ranging from "totally agreeing", "agreeing", "disagreeing" and "totally disagreeing", in which the score obtained with the scale can range from 0 to 30 , the closer to 0 the better the self-esteem measure, on the other hand, the closer to 30 the more unsatisfactory ${ }^{(7)}$.

\section{Procedures}

The data were collected on the days and times when the studio was opened, preferably before or after the class time, without a specific shift. The researcher applied the questionnaires in the form of interviews.

\section{Statistical analysis}

A descriptive analysis of the sample studied was performed. Quantitative variables were presented in mean and standard deviation, and categorical variables in absolute and relative frequencies (percentage) and presented through graphs and or tables. The homogeneity of the samples was studied using Student's t-tests or Mann-Whitney tests for continuous variables, according to the normality of the samples, or chi-square test for categorized variables.

\section{Ethical aspects}

This research was sent to Plataforma Brasil and approved (number: 1.892.112) and issued by the Hospital and Maternity São Domingos, São Luís, MA, Brazil. All interviewees have confirmed their willingness to participate in the study by signing the Informed Consent Form.

\section{RESULTS}

The study interviewed 60 women, 30 women practicing Pilates and 30 women in the control group, in order to verify if there was a difference between the quality of life and the self-esteem of women. Table 01 presents the socio-demographic data of the sample that shows the similarity between the groups.

Table 01. Sociodemographic data for the Pilates group and control group.

\begin{tabular}{|c|c|c|c|}
\hline Data & Pilates group & Control group & p ppP \\
\hline Age (years) & 37.7 & 33.3 & 0.17 \\
\hline Education & & & 0.71 \\
\hline Elementary & $6.7 \%(n=2)$ & $10 \%(n=3)$ & \\
\hline High school & $40 \%(n=12)$ & $46.7 \%(n=14)$ & \\
\hline Higher education & $53.3 \%(n=16)$ & $43.3 \%(n=13)$ & \\
\hline Marital status & & & 0.53 \\
\hline Single & $46.7 \%(n=14)$ & $53.3 \%(n=16)$ & \\
\hline Married & $40 \%(n=12)$ & $43.3 \%(n=13)$ & \\
\hline Divorced & $10 \%(n=4)$ & $3.3 \%(n=1)$ & \\
\hline Work & & & 0.15 \\
\hline Yes & $80 \%(n=24)$ & $63.3 \%(n=19)$ & \\
\hline No & $20 \%(n=6)$ & $36.7 \%(n=11)$ & \\
\hline House & & & 0.46 \\
\hline Own & $93.3 \%(n=28)$ & $66.7 \%(n=20)$ & \\
\hline Rent & $3.3 \%(n=1)$ & $16.7 \%(n=5)$ & \\
\hline Others & $3.3 \%(n=1)$ & $16.6 \%(n=5)$ & \\
\hline *BMI & & & 0.75 \\
\hline Low weight & $6.7 \%(n=2)$ & $10.1 \%(n=3)$ & \\
\hline Adequate & $60 \%(n=18)$ & $50 \%(n=15)$ & \\
\hline Overweight & $23.3 \%(n=7)$ & $33.3 \%(n=10)$ & \\
\hline Obese & $10 \%(n=3)$ & $6.7 \%(n=2)$ & \\
\hline
\end{tabular}


The SF-36 questionnaire was used to evaluate the quality of life of Pilates women and control subjects, as shown in table 02. Regarding the SF-36 questionnaire, a difference between the groups in the general health status $(p=0.001)$ and emotional aspects $(p=0.001)$ was found with better results for the Pilates group.

In order to evaluate the self-esteem, they were submitted to the Rosenberg Self-esteem Scale as shown in table 03. Were found as a result the value 5.46 for the Pilates group and 8.16 for the control group $(p=0.05)$. Remembering that the closer to zero, the better the self-esteem evaluation. This result highlighted the difference in scores between the two groups, with a better response for the Pilates group, even though it was only in absolute numbers and with a slight tendency to statistical significance.

\section{DISCUSSION}

The investigation of quality of life, and more recently of self-esteem, in a global way has been the object of many studies related to the practice of physical activity. The differential of this study is the evaluation of these two constructs in Pilates women comparing their results to a sedentary group.

As results were found in the Pilates group characteristics common to most participants, such as age greater than 30 years, single marital status, higher education level, women in full working activity, with their own house and appropriate BMI.

To evaluate the quality of life of women who practice Pilates and the control group, the SF-36 questionnaire was applied. Regarding this questionnaire, we found differences between the groups in the domains of general health and emotional aspects with better scores for the Pilates group. One study

Table 02. Data referring to quality of life of the Pilates group and the control group.

\begin{tabular}{lccl}
\hline \multicolumn{1}{c}{ SF-36 } & Pilates group & Control group & \multicolumn{1}{c}{$\mathbf{P}$} \\
\hline FUNCTIONAL CAPACITY & 90.0 & 85.0 & $=0.24$ \\
LPA & 100.0 & 75.0 & $=0.15$ \\
GHS & 77.7 & 57.1 & $<0.001^{*}$ \\
PAIN & 67.0 & 64.5 & $=0.67$ \\
VITALITY & 67.6 & 59.3 & $=0.13$ \\
SOCIAL ASPECTS & 87.5 & 75.0 & $=0.24$ \\
EMOTIONAL ASPECTS & 100.0 & 66.6 & $=0.001^{*}$ \\
MENTAL HEALTH & 77.0 & 67.3 & $=0.05$ \\
\hline
\end{tabular}

* = significant statistical value; $\mathrm{LPA}=$ Limitation by physical aspects, $\mathrm{GHS}=$ General health status; Statistical tests: T-Student and Mann Whitney; $p<0.05$.

Table 03. Self-esteem scale data for Pilates and control groups.

\begin{tabular}{cccc}
\hline Self-esteem & Pilates Group & Control Group & $\mathbf{p}$ \\
\hline 5.46 & 8.16 & 0.05 \\
\hline
\end{tabular}

Statistical test: Mann Whitney; $\mathrm{p}<0.05$. evaluated the effects of Pilates on a sample of 47 adults, male and female, for a period of 6 months on the criteria: flexibility, body composition and general health status; and the results showed that there was no statistically significant change in these domains between the time, however, the study did not have control group and consequently, there was no comparison between the groups ${ }^{(12)}$.

Other authors did not find a statistically significant difference between groups for the general health domain of SF-36 among a group of women who practice Pilates and a bodybuilding group ${ }^{(13)}$. This study also did not have a control group. Other studies have evaluated the quality of life in individuals, who practice Pilates, with diseases such as low back pain, fibromyalgia, osteoporosis, menopause, ankylosing spondylitis and breast cancer ${ }^{(14-19)}$.

We did not find in the literature a research in methodological equivalence in terms of gender of the sample and methodological design of the study. We credit the fact that the general health of the Pilates group has been superior to the sedentary group due to the beneficial effects related to the prevention of diseases that Pilates usually provides to its practitioners and are already well described in the literature.

Considering the emotional aspects, it can be affirmed that a significant difference was found between the values of the group that practice the method compared to the group that does not practice it, with better results for women who practice Pilates. In the study that also evaluated quality of life, it was verified that the score of the emotional aspects were statistically better in the Pilates group than in the bodybuilding group $^{(13)}$.

The present study agrees with a research that associated positive change in the emotional aspects domain with the practice of the Pilates Method, which leads us to think that if performed regularly and following the basics, the Pilates method can contribute to changes in the quality of life of the individual ${ }^{(20)}$. These results corroborate with a study that identified one of the main benefits provided by Pilates to its practitioners: the emotional well-being ${ }^{(21)}$. Nevertheless, this study diverges from a study in which no significant differences were found either in the emotional aspect or in the mental health domain, which, according to the authors, may have been caused because the time of the practice of the method was insufficient to express a significant change ${ }^{(22)}$. It is noteworthy that of the studies cited above, only one study has an equivalent methodological design, although the comparison group was different ${ }^{(13)}$.

In order to analyze the self-esteem of both groups, a better response was found for the Pilates group when compared to the control group. This result, even though it was only in absolute numbers, tended to be statistically significant $(p=0.05)$ and emphasized the difference between the scores of the two groups. Only one study included the Pilates method and the evaluation of self-esteem and this study presented a 
differentiated methodological design, making it impossible to equate ${ }^{(23)}$.

Despite the small sample size, we noticed that the present study showed a significant difference with better responses for the Pilates group in two domains of the SF-36 and showed a significant statistical tendency in the evaluation of self-esteem also with better responses for the Pilates group.

This was an observational and cross-sectional study involving Pilates associated with the assessment of quality of life and self-esteem of women. Although Pilates seems to be a well-discussed subject in the literature, it has been noticed that little has been discussed about the practice of the Pilates method in healthy women and more specifically, the interference of the same in the self-esteem of these women. This study had as limitations: the size of the sample, the absence of more specific questions regarding the health status of both groups and also the time of practice of the physically active group method. For this reason and based on the above considerations, we suggest that new studies be carried out in order to contemplate the gaps existing on the said subject.

\section{CONCLUSION}

Women who practice Pilates present some aspects of quality of life in superiority to those who do not practice it.

\section{AUTHOR'S CONTRIBUTION}

FRAO: data collection; OLMG: offered support to the student; AF: data analysis; MCS: final review of the article; RTJC: analysis and interpretation of data.

\section{CONFLICTS OF INTEREST}

The author(s) declare that they have no competing interests.

\section{AUTHOR DETAILS}

${ }^{1}$ Undergraduate student of the Physiotherapy course of the Faculdade Santa Terezinha - CEST, São Luís, MA

2 Physiotherapist, Master in Collective Health, Assistant Professor of the Physiotherapy course of the Faculdade Santa Terezinha - CEST, São Luís, MA

${ }^{3}$ Economist, Doctor in Administration, Adjunct Professor of the Physiotherapy course of the Faculdade Santa Terezinha - CEST, São Luís, MA.

${ }^{4}$ Physiotherapist, Doctor in Rheumatology, Adjunct Professor of the Physiotherapy course and the Mater program in Collective Health of the Faculdade de Ciências da Saúde do Trairi - Universidade Federal do Rio Grande do Norte, FACISA/UFRN

\section{REFERENCES}

1. De Vitta AL, Padovani, CR. Saúde percebida em homens e mulheres sedentários e ativos, adultos jovens e idosos . Saluvita. 2006;(25):20-6.

2. Mcauley E, Elaysky, S, Motl RW et al. Physical Activity,Self-Efficacy, and Self- Esteem: Longitudinal Relationships in Older Adults. Journal of Gerontology B Psychological Sciences Social Sciences. 2005;(60):268-75.

3. Gonçalves AKS, Canário ACG, Cabral PUL, da Silva RAH, Spyrides MHC, Giraldo PC, et al. Impacto da atividade física na qualidade de vida de mulheres de meia idade: estudo de base populacional. Rev Bras Ginecol Obstet. 2011;33(12): 408-13.
4. Ciconelli RM, Ferraz MB, Santos W, Meinão I, Quaresma MR. Tradução para a língua portuguesa e validação do questionário genérico de avaliação de qualidade de vida SF-36 (Brasil SF-36). Rev bras reumatol. 1999;39(3):14350 .

5. Seidl EMF, Zannon CML. Qualidade de vida e saúde: aspectos conceituais e metodológicos. Cadernos de saúde pública. 2004;20:580-8.

6. Pereira EF, Teixeira CS, Santos A. Qualidade de vida: abordagens, conceitos e avaliação. Rev. Bras. Educ. Fís. Esporte. 2012;26(2):241-50.

7. Dini GM, Quaresma MR, Ferreira LM. Adaptação cultural e validação da versão brasileira da escala de autoestima de Rosenberg. Revista Sociedade Brasileira de Cirurgia Plástica. 2004;19(1):41-52.

8. Marques RG.; Bittar AJ.; Ribeiro CA. Avaliação da imagem corporal e autoestima em indivíduos ativos praticantes e não praticantes de Pilates. CEAFI. 2009;13:1-24.

9. Anderson BD, Spector A. Introduction to Pilates- -based rehabilitation. Orthop Phys Ther Clin N Am. 2000;9(3):395-410.

10. Silva ALG. da; Mannrich G. Pilates na Reabilitação: Uma revisão sistemática. Fisioterapia em movimento. 2009;22(3):449-455.

11. Picolli F. Efeitos do treinamento proporcionado pelo Método Pilates Clássico nas Aptidões Físicas em mulheres saudáveis: um Ensaio Clínico Controlado. [dissertation]. Porto Alegre: Universidade Federal do Rio Grande do Sul; 2010.

12. Segal NA.; Hein J.; Basford, JR. The Effects of Pilates Trainig on flexibility and Body Composition: An Observational Study. Archives of Physical Medicine and Rehabilitation. 2004;85:1977-8.

13. Lara S, Wendt P, Da Silva ML. Comparação da qualidade de vida em mulheres praticantes de Pilates e musculação. Conscientia e saúde. 2014;13(1):78-82.

14. Kofotolis N, Kellis E, Vlachopoulos S, Gouitas I. Effects of Pilates and trunk strengthening exercises on health-related quality of life in women with chronic low back pain. Journal of Back and Musculoskeletal Rehabilitation. 2016;29(4): 649-59.

15. Ekici G, Unal E, Akbayrak T, Vardar-Yagli N, Yakut Y, Karabulut, E. Effects of active/passive interventions on pain, anxiety, and quality of life in women with fibromyalgia: Randomized controlled pilot trial. Women Health. 2017;57(1):88-107.

16. Hita-Contreras F, Martínez-Amat A, Cruz-Díaz D, Pérez-López FR. Fall prevention in postmenopausal women: the role of Pilates exercise training. Climacteric. 2016;19(3):229-33.

17. Angın E, Erden Z, Can F. The effects of clinical pilates exercises on bone mineral density, physical performance and quality of life of women with postmenopausal osteoporosis. J Back Musculoskelet Rehabil. 2015;28(4):849-58.

18. Altan L, Korkmaz N, Dizdar M, Yurtkuran M. Effect of Pilates training on people with ankylosing spondylitis. Rheumatol Int. 2012;32(7):2093-9.

19. Eyigor S, Karapolat H, Yesil H, Uslu R, Durmaz B. Effects of pilates exercises on functional capacity, flexibility, fatigue, depression and quality of life in female breast cancer patients: a randomized controlled study. Eur J Phys Rehabil Med. 2010; 46(4):481-7.

20. Bellinate LMA. Repercussão do método Pilates solo e bola na qualidade de vida dos servidores da Universidade Federal de Mato Grosso do SulCampus Campo Grande. [dissertation]. Campo Grande: Universidade Católica Dom Bosco; 2015.

21. Herrera-Gutiérrez E, Olmos-Soria M, Brocal-Pérez D. Psychological effects of the practice of Pilates Method in a university sample. Anal. Psicol. [internet]. 2015; 31(3).

22. Gonçalves OS, Lima PO. Percepção de saúde e Qualidade de vida: Um inquérito com praticantes de pilates. Fisioterapia e saúde funcional. 2014;3(1):11-7.

23. Küçük F, Livanelioglu A. Impact of the clinical Pilates exercises and verbal education on exercise beliefs and psychosocial factors in healthy women. J Phys Ther Sci. 2015;27(11):3437-43. 